\title{
História e Educação: as instituições escolares dominicanas-anastasianas em Goiás
}

History and Education: dominican-anastasian school institutions in Goiás

Historia y Educación: instituciones escolares dominico-anastasianas en Goiás

Cesar Evangelista Fernandes Bressanin Universidade Federal do Tocantins (Brasil)

https://orcid.org/0000-0003-1221-2353

http://lattes.cnpq.br/4737722834785056 kaeserevangelista@gmail.com

Maria Zeneide Carneiro Magalhães de Almeida Pontifícia Universidade Católica de Goiás (Brasil)

https://orcid.org/0000-0003-2220-9932

http://lattes.cnpq.br/5736362178244406

zeneide.cma@gmail.com

\section{Resumo}

O objetivo do estudo aqui proposto é apresentar a trajetória histórica das instituições escolares dominicanas-anastasianas no estado de Goiás, entre o final do século XIX e a década de 1960. Aportado numa pesquisa bibliográfica e documental, a partir dos estudos sobre história das instituições escolares e dos pressupostos da História Cultural, o texto explicita a filosofia educativa da Congregação das Irmãs Dominicanas de Nossa Senhora do Rosário de Monteils, de origem francesa, que instalou-se no Brasil em 1885 e suas fundações no estado de Goiás no recorte temporal citado. Sem considerar as especificidades destas instituições escolares, o trabalho traça o itinerário das mesmas e suas contribuições para a história da educação goiana.

Palavras-chave: Educação dominicana-anastasiana. Goiás. História da educação. 


\begin{abstract}
The goal of this study is to present the historical trajectory of Dominican-Anastasian school institutions in the state of Goiás between late 19th century and the 1960s. Based on bibliographic and documentary research, and supported by studies on the history of school institutions and the assumptions of Cultural History, the text explains the educational philosophy of the Congregation of the Dominican Sisters of Our Lady of the Rosary of Monteils, of French origin, which settled in Brazil in 1885, and its foundations in the state of Goiás in the aforementioned time cutout. Without considering the specificities of these school institutions, this work traces their itinerary and their contributions to the history of education in Goiás.
\end{abstract}

Keywords: Dominican-anastasian education. Goiás. History of education.

\title{
Resumén
}

El objetivo del estudio propuesto aquí es presentar la trayectoria histórica de las instituciones escolares dominico-anastasianas en el estado de Goiás, entre fines del siglo XIX y la década de 1960. Apoyado en una investigación bibliográfica y documental, basada en estudios sobre la historia de las instituciones escolares y los supuestos de la Historia Cultural, el texto explica la filosofía educativa de la Congregación de las Hermanas Dominicas de Nuestra Señora del Rosario de Monteils, de origen francés, que se estableció en Brasil en 1885 y sus fundaciones en el estado de Goiás en el período mencionado. Sin considerar las especificidades de estas instituciones escolares, el trabajo rastrea su itinerario y sus contribuciones a la historia de la educación en Goiás.

Palabras claves: Educación dominica-anastasiana. Goiás. Historia de la educación. 


\section{Introdução}

A história da educação de Goiás é marcada por inúmeras iniciativas tanto por parte do poder público como de instituições privadas. A influência da Igreja Católica Apostólica Romana, no final do século XIX e por longas décadas do século XX, articulou avanços significativos para o mundo educacional goiano da época.

O propósito deste texto é expor o itinerário das instituições escolares da educação dominicana-anastasiana no estado de Goiás no período de 1880 a 1960. De maneira especial, o texto enfatiza os colégios, escolas e institutos fundados e mantidos pela Congregação das Irmãs Dominicanas de Nossa Senhora do Rosário de Monteils no cerrado goiano.

Estas instituições escolares embasaram suas finalidades e sua filosofia na proposta educativa de seus fundadores: São Domingos de Gusmão, progenitor da Ordem Dominicana no ano de 1216, originando o termo educação dominicana e Madre Anastasie, genitora da Congregação de Monteils em 1850, originando o termo educação anastasiana.

A filosofia educativa dominicana-anastasiana sintetiza-se no intuito de promover uma educação que preza pela formação integral do ser, pautada em valores humanos e cristãos que evidenciam a individualidade e potencialidade do sujeito na perspectiva de transformação das pessoas (SMITH, 2015, p. 30).

Hannah Arendt, em uma de suas magníficas obras, Homens em tempos sombrios (2008), faz alusão a necessidade de extrairmos do passado suas riquezas. Através de sua metafórica reflexão, referindo-se à Walter Benjamim, ela acena para a necessidade de reunirmos 'fragmentos do pensamento' e ajuntarmos memórias como 'um pescador de pérolas que desce ao fundo do mar, não para escavá-lo e trazer à luz, mas para extrair o rico e o estranho, as pérolas e o coral das profundezas, e trazê-los à superfície" (ARENDT, 2008, p. 222).

Seria o pensamento de Arendt pistas para a pesquisa e estímulo para o pesquisador? Tornar-se um 'pescador de pérolas', fazer um achado, mergulhar no passado seriam pistas e propostas de um constructo da história? Trazer à superfície 'pérolas e corais' de memórias que quase se esvaneceram e foram à ruína com o tempo, contribui para a história da educação?

De certo que, ao trazer à tona, essas riquezas se transformam em tesouros, fragmentos do pensamento que irradiam saber, revelam trajetórias e manifestam experiências. Quantas possibilidades se abrem frente a essa perspectiva para a pesquisa sobre instituições escolares. Por isso, propor-se a reconstruir historicamente "instituições escolares brasileiras implica admitir a existência dessas instituições que, pelo seu caráter durável, têm uma história que nós não apenas queremos como necessitamos conhecer" (SAVIANI, 2007, p. 24).

Assim, o que se alvitra aqui são respostas ao estímulo, as pistas e as possibilidades propostos por Arendt. Aportado numa pesquisa bibliográfica e documental, o presente artigo pretende trazer à superfície 'pérolas e corais' escondidos em algum lugar, produzir a história, revelar e compilar traços do passado das instituições escolares fundadas e mantidas por uma congregação religiosa católica feminina em Goiás.

Sabe-se que a forte presença de congregações religiosas no Brasil no final do século XIX e até meados do século XX marcou a sociedade brasileira. Congregações estrangeiras, em sua maioria, mas também congregações genuinamente brasileiras, em sua minoria, fizeram do Brasil um grande campo de missão no aspecto religioso, pastoral e educacional. Em plena organização do estado republicano brasileiro e da expansão do pensamento liberal muitas congregações, de origem europeia, instalaram-se em diversos lugares do Brasil (BITENCOURT, 2017).

A Europa viveu intensamente um grande processo de laicização do ensino no século XIX. Itália e França chegaram a expulsar de seus territórios as ordens e congregações católicas. Assim, "os interesses da Igreja, fragilizada na Europa e em processo de legitimação de uma 
política centralizada em Roma, fizeram-na considerar a América Latina como um espaço de forte investimento" (BITTENCOURT, 2017, p. 37-38).

No Brasil, a Igreja Católica também enfrentava grande enfraquecimento nas relações com poder instituído. A influência liberal regalista no clero brasileiro, a Questão Religiosa de 1872 e a necessidade de se afirmar como instituição, levaram os bispos brasileiros a reagir. Ancorado nas diretrizes do Concílio Vaticano I, nas propostas de Leão XIII explícitas em suas encíclicas e no incentivo dado à América Latina, o episcopado brasileiro empreitou uma grande reforma do catolicismo nacional. Uma das diretrizes desta reforma pautava-se na abertura de escolas católicas visto que o campo educacional brasileiro de então carecia de expertises (BITENCOURT, 2017)

Em que pese, o campo educacional foi um dos campos mais promissores da presença das congregações católicas no Brasil, que com a ajuda da elite eclesiástica brasileira (MICELLI, 2009) assumiram em muitas dioceses trabalhos educacionais, ocupando espaços próprios de um Estado republicano, como mostram as pesquisas e trabalhos de AZZI (1983), MOURA (2000), LEONARDI (2010), ROUX (2014), BITTENCOURT (2017) entre outros.

A Congregação das Irmãs Dominicanas de Nossa Senhora do Rosário de Monteils, de origem francesa, foi a instituição católica que, a convite e amparada pelo episcopado goiano, fez do sertão e do cerrado lugar de implantação e expansão de seu projeto educativo e de contribuição aos planos de reforma do catolicismo nos parâmetros do processo ultramontano e de romanização.

\section{História da Educação dominicana-anastasiana: um itinerário}

Depois de seis séculos de trabalho religioso e missionário em diversos lugares do mundo, a Ordem Dominicana, ou dos Pregadores como é oficialmente reconhecida pela Igreja Católica, chegou ao Brasil no ano de 1881. Foi o então bispo de Goiás, Dom Claudio José Gonçalves Ponce de Leão, o responsável pela concretização do projeto de instalação dos frades dominicanos em sua diocese.

Frei Raimundo Madré e Lázaro Melizán foram os primeiros missionários, vindos do convento de São Maximino na França, a instalarem-se no Brasil. Chegaram à Uberaba no dia 31 de outubro de 1881. A região do triângulo mineiro pertenceu à Diocese de Goiás até o ano de 1907, Ali, através do movimento religioso católico de evangelização e missão popular foram colaboradores do bispo diocesano no projeto de renovação da Igreja empreendido pelo episcopado brasileiro no final do século XIX e início do século XX.

$\mathrm{Na}$ Diocese de Goiás, ainda sob o governo de Dom Claudio, a Ordem Dominicana abriu conventos na cidade de Goiás em 1883, Porto Nacional em 1886, Formosa em 1905 e ao longo do século $\mathrm{XX}$ em diversas outras dioceses brasileiras. O historiador eclesiástico Cônego Trindade em sua obra Lugares e Pessoas afirmou que "[...] onde ia o escapulário do padre dominicano, logo em seguida, em se completando, lá vinha o hábito da irmã religiosa dominicana" (SILVA, 2006, p. 420). Riolando Azzi afirmou que a vinda dos religiosos dominicanos para o Brasil abriu caminhos "para a vinda das Irmãs Dominicanas do SS. Rosário, cuja atividade principal foi a educação da juventude" (AZZI, 1986, p. 24).

De certo, à dos padres dominicanos já bem instalados e acolhidos no sertão brasileiro e incentivados por Dom Cláudio, as primeiras religiosas dominicanas de Monteils chegaram ao Brasil. No início de maio de 1885 um pequeno grupo de seis irmãs, Maria José, Maria Reginalda, Maria Eleonora, Maria Hildegarda, Maria Otávia e Maria Juliana saíram do porto de Bordeaux e aportaram no Rio de Janeiro de onde empreenderam uma longínqua viagem até Uberaba. Seis mulheres, seis Marias em direção ao mundo completamente estranho num trem a vapor até Ribeirão Preto e em carros puxados por juntas de bois até o triângulo mineiro. Começava uma saga de missão e de educação que alcançou alguns 
recônditos e centros do Brasil na perspectiva de um projeto educativo fundamentado na formação integral da pessoa humana a partir de valores éticos e cristãos que valorizam o sujeito em sua individualidade e potencialidade (CONGREGAÇÃO DAS IRMÃS DOMINICANAS DE NOSSA SENHORA DO ROSÁRIO DE MONTEILS, 2016).

Quando as primeiras missionárias dominicanas chegaram em Uberaba em julho de 1885 foram alojadas e instaladas na Santa Casa de Misericórdia da cidade. Inicialmente, dedicaram-se à tarefa de cuidar dos enfermos tanto no hospital como em seus domicílios, unindo-se à tarefa apostólica e pastoral dos frades dominicanos. No entanto, a preparação das atividades educativas para abrir algumas classes para atender às jovens e às crianças da cidade aconteciam concomitante ao trabalho com a saúde (LOPES, 1986). "Educação e Saúde, dois princípios propostos pela fundadora, Madre Anastasie, duas metas a serem alcançadas por aquelas estrangeiras" (CONGREGAÇÃO DAS IRMÃS DOMINICANAS DE NOSSA SENHORA DO ROSÁRIO DE MONTEILS, 2016).

O Colégio Nossa Senhora das Dores foi a primeira instituição escolar criada pelas Irmãs Dominicanas de Nossa Senhora do Rosário de Monteils no Brasil. Suas atividades começaram bem tímidas em 1885. No princípio eram seis irmãs e seis alunas, duas internas e quatro externas. "A Congregação das Irmãs Dominicanas foi pioneira quanto à implantação de colégios no interior do triângulo mineiro" (MELO, 2002, p. 45). Ano após ano, o número de alunas foi crescendo, no primeiro ano o Colégio atraiu mais de uma centena de alunas e chegou ao número de quase $250 \mathrm{em} 1895$ (LOPES, 1986). A oferta de uma educação feminina assumida pela congregação no Colégio Nossa Senhora das Dores era permeada de "prática e processos nos quais a sociedade pôde cumprir seus anseios, moldando, dentro dos padrões conservadores, a formação de uma mulher preparada para as doçuras do lar e da maternidade" (MELO, 2002, p. 79) conforme os padrões sociais vigentes na época.

O Colégio Nossa Senhora das Dores cresceu, mantém-se em funcionamento até os dias atuais com diferentes modalidades de ensino desde meados do século XX e é tido como um "centro de radiação e referência" para toda a Congregação de Monteils e para a educação dominicana-anastasiana no Brasil (CONGREGAÇÃ̃O DAS IRMÃS DOMINICANAS DE NOSSA SENHORA DO ROSÁRIO DE MONTEILS, 2016, p. 36).

Este itinerário educacional dominicano-anastasiano marcado por continuidades e rupturas possibilitou 'espaços de experiência' que marcaram a trajetória da congregação e de suas instituições escolares e possibilitaram 'horizontes de expectativas' que entrelaçaram passado e futuro (KOSELLECK, 2006) num caminho que se fez de sonhos e anseios.

Em alguns momentos a educação dominicana precisou recuar, colégios e institutos educacionais foram fechados por diversas razões, entre elas, a necessidade de consolidação de outras instituições, as questões econômicas financeiras e a falta de vocações para a vida religiosa da congregação. Em outros momentos foi preciso expandir, pois novos horizontes de expectativas se abriram com novos espaços de experiências que se projetavam melhor para o futuro.

Assim, para obter respostas a alguns questionamentos e inquietações, para ter acesso a algumas experiências do passado, para trazer um pouco do itinerário da educação dominicanaanastasiana no estado de Goiás foi preciso juntar indícios, reunir os 'cacos da história' que possibilitaram a construção dessa narrativa histórica que aqui se apresenta. Sem o intuito de estabelecer verdades e certezas, pois "tudo o que foi um dia poderá vir a ser contado de outra forma, cabendo ao historiador elaborar uma versão plausível, verossímil, de como foi" (PESAVENTO, 2005, p. 51), este texto quer contribuir para a construção de um 'discurso sobre o passado' e abrir possibilidades de novas interrogações e de outros questionamentos sobre as instituições escolares dominicanas-anastasianas em Goiás que portam um arsenal de fontes e de informações fundamentais para a história da educação (GATTI JR., 2002). 


\section{Instituições escolares dominicanas-anastasianas em Goiás}

Com o crescimento do colégio Nossa Senhora das Dores em Uberaba e o pedido do bispo de Goiás para a abertura de uma escola na sede da diocese, outras irmãs vieram da França com o objetivo de fortalecer e expandir a missão educacional no Brasil. O segundo grupo de religiosas chegou ao país em junho de 1889 e permaneceu em Uberaba por alguns meses para descansar e familiarizar-se com a língua portuguesa.

Novas irmãs, com nomes bem franceses chegam a Uberaba, MG: Irmãs Jeanne-Marie, Maria Emmanuel, Marie Antoinette e Maria Isabelle. Estas e mais outras quatro, que já estavam no Colégio Nossa Senhora das Dores de Minas, são designadas para dirigir-se a Goiás. Vem buscá-las uma comitiva daquele Estado, com 30 mulas, e poucos empregados. Como conselheiro espiritual, sobretudo, vem o padre Gallais, O.P., delicado e paternal. Com provisões básicas e colchões que se enrolavam, preparam-se para 120 léguas de caminho, cumpridas em etapas de 24 a $30 \mathrm{~km}$ diários. Sempre encontram boa acolhida entre os raros moradores do percurso (CONGREGAÇÃO DAS IRMÃS DOMINICANAS DE NOSSA SENHORA DO ROSÁRIO DE MONTEILS, 2016, p. 31).

Com a chegada das Irmãs no dia 05 de setembro de 1889 inaugurou-se em Goiás o Colégio Sant'Anna, que iniciou suas atividades no dia $1^{\circ}$ de outubro daquele ano com uma classe gratuita, cinco alunas internas e cem alunas externas. O Jornal O Popular do dia 14 de setembro de 1984 trouxe uma reportagem por ocasião dos 95 anos da chegada das Irmãs à cidade de Goiás e relatou o seguinte:

Lembranças saudosas de tempos de lutas, planos e alegrias se juntam à satisfação de muita realização e trabalho. Isto é um pouco do que compõe o clima de comemorações do centenário da chegada das Irmãs dominicanas ao Brasil, em 1884 e dos 95 anos de Goiás, para a fundação do Colégio Sant 'Ana, em 1889 na cidade de Goiás. Setembro, dia 5, às 11 horas da manhã. Era o ano marcado para uma grande mudança de perspectivas no ensino e da cultura de Goiás [...] Bandas de música, fogos de artifício, o clero regular, toda a gente da cidade e D. Claudio Leão compunham a comitiva de recepção com muita alegria pela chegada tão esperada das missionárias que vinham de Uberaba a cavalo, e aportavam depois de 28 dias de viagem e desconforto. Cercadas inicialmente de muita curiosidade de toda a população, que, todavia pressentia nelas a confiança e responsabilidade do trabalho novo, 95 anos depois elas oferecem o saldo de uma extensa folha de serviços cumpridos em prol não só do ensino, mas das obras sociais em geral da cidade e do estado [...]. (O POPULAR, Goiânia, 1984 apud MELO, 2013, p. 54 - grifo nosso).

De fato, uma nova era educacional iniciou em Goiás com a abertura do Colégio Sant'Anna. Como a capital da província não contava com um sistema de ensino estruturado, nem da rede pública, nem da rede privada e não existia preocupação para a com a instrução primária e secundária para o sexo feminino, o incentivo do governo para com a iniciativa privada no ensino talvez justifique a calorosa recepção que as Dominicanas tiveram ao chegarem à Goiás (CANESIN; LOUREIRO, 1994). 
Como a maioria das alunas que acorriam ao Colégio Sant'Anna provinham de famílias abastadas da cidade e da circunvizinhança, havia uma preocupação das irmãs em acolher as crianças pobres (VALLE, 1989) e destinavam salas para estas alunas (CAMARGO, 2014). A carta pastoral de Dom Eduardo Duarte da Silva, sucessor de Dom Claudio elucida bem isso.

Não podereis negar que as heroicas religiosas dominicanas que por amor da educação e ensino de vossas filhas, abandonarão pátria, família, commodos da vida e vierão aqui affrontar nosso clima, almodar-se a nosso hábito e consumir n'esta Diocese sua mocidade, sua saúde, suas forças, sua vida. Não podereis pagar negar os immensos beneficio que elas prestão a instrução e educação tanto das filhas do rico, com ás pobrezinha, filhas dos menos favorecidos da fortuna, do artista, do operário e do proletariado (CARTA PASTORAL, 1897 apud CAMARGO, 2014 sic)

Para que o empreendimento educacional do Colégio Sant'Anna pudesse atender às meninas carentes o incentivo do poder púbico foi importante, pois nem a Diocese de Goiás e nem a Congregação contava com divisas financeiras para um investimento tão alto. Por isso, "gestões feitas juntos aos deputados por pessoas ligadas às Irmãs Dominicanas viabilizaram a aprovação, em 22/6/1896, da Lei no 113 , que concedia às Irmãs Dominicanas a quantia de - um cento e duzentos mil reais anuais, como auxílio ao colégio que dirigiam" (CANESIN; LOUREIRO, 1994, p. 44).

O Colégio Sant'Anna ofereceu à juventude de Goiás e região uma educação particular a partir de valores católicos já impregnados na sociedade goiana. No ano de 1904, a pedido das famílias locais, o Colégio abriu uma sala do curso primário para os meninos, na modalidade de externato, que chegaram ao número de 40 no final do ano (CAMARGO, 2014).

Em 1907 o Colégio Sant'Anna foi equiparado à Escola Normal Pública pela lei no 1.301 de 18/07/1907 (BRZEZINSKI, 1987; BRETAS, 1991). No entanto, por questões de adaptação e reorganização somente em 1915 o curso normal passou a funcionar no Colégio Sant'Anna e propiciou a formação de muitas professoras normalistas para a cidade de Goiás e região.

as experiências vivenciadas nos e pelos colégios católicos, a equiparação à Escola Normal Oficial, além de ser um interesse do Estado pela expansão do ensino particular, garantiria espaço, por parte das escolas confessionais, para veiculação das ideias religiosas e formação de mentalidades afinadas com as concepções da Igreja Católica e das famílias tradicionais de Goiás (CAMARGO, 2014, p.86).

Durante todo o século XX, o Colégio Sant'Anna viveu seu apogeu. Ofertou uma educação de referência para as moças através da educação primária e da escola normal, ofereceu educação mista à sociedade vilaboense e adequou-se às legislações educacionais brasileiras com a oferta de outras modalidades de ensino. No entanto, ao adentrar o século XXI, o Colégio Sant'Anna, de educação dominicana-anastasiana, sofreu com as agruras da redução das matrículas, da concorrência do mercado capitalista, da falta de incentivos e das questões internas da congregação religiosa, desfalcada no número de vocações. Depois de 126 anos de prática educativa e contribuição para a história da educação goiana, como nos revelam os trabalhos de Gonçalves (2004) e Camargo (2014), o Colégio Sant'Anna fechou suas portas no ano de 2015. 
A filosofia educativa dominicana-anastasiana expandiu-se pelo estado de Goiás. Já eram dois colégios consolidados no início do século XX no território da Diocese Goiana ${ }^{1}$. Assim, "em 1902, a pedido de Dom Eduardo Silva, sucessor de D. Claudio José Gonçalves Ponce de Leão, as Irmãs abriram outro colégio em Bela Vista (Goiás). Esta casa servia como ponto de ligação entre Uberaba e a capital de Goiás" (LOPES, 1986, p. 81). O colégio recebeu o nome de Santa Catarina de Sena e funcionou até 1911, quando as Irmãs que ali moravam foram designadas para o Colégio de Formosa, fundado em 1910. São poucas as informações e registros acerca desta instituição escolar que funcionou em regime de internato oferecendo o curso primário para meninas.

Desde 1886 os frades dominicanos estavam presentes em Porto Nacional e a Ordem Dominicana usou de diversos dispositivos nesta missão em pleno sertão do antigo norte de Goiás, hoje estado do Tocantins. Os dispositivos adotados foram "as missões, as desobrigas, as construções e os projetos educativos" utilizados "como estratégias acopladas às ideias do processo civilizador [...] que comungavam com as propostas de reforma da Igreja Católica no contexto do final do século XIX e início do século XX” (BRESSANIN, 2017, p. 20).

Para ajudar no desenvolvimento dos projetos educativos em Porto Nacional o Convento Santa Rosa de Lima solicitou a presença das dominicanas de Monteils na intenção da abertura de um colégio destinado à educação das moças, visto que os frades que estavam assinados em Porto Nacional mantinham uma organização educativa para os rapazes através da escola, banda de música e grupo de moços (BRESSANIN, 2017). Assim,

Em Porto Nacional, as Dominicanas do Santíssimo Rosário de Monteil, chegaram no município no dia 30 de agosto de 1904. Neste mesmo ano, foi criado o Colégio Sagrado Coração de Jesus. Sua instalação física se deu em uma casa do então intendente municipal, Cel. Frederico Ferreira Lemos. Com a colaboração do poder público, das famílias portuenses, pertencentes à rede de relações sociais das dominicanas fomentaram iniciativas para que, em 1906, elas se instalassem na sede própria do Colégio (DOURADO, 2010, p. 134, sic).

Foram fundadoras do Colégio Sagrado Coração de Jesus quatro religiosas francesas Madre Maria Ignez, Irmã Maria Rafael, Irmã Maria André e a Irmã Maria Fernanda e que deram este nome ao colégio em razão da devoção, tipicamente francesa, ao Coração de Jesus. De acordo com Lopes (1986), a Congregação das Dominicanas de Monteils mantinha essa devoção em suas práticas religiosas, visto que a fundadora, Madre Anastasie, sempre consagrava suas seguidoras à este Coração e "com ele dialogava na intimidade. Nessa fonte hauria sua fortaleza. Ele é a sua confiança, sua misericórdia, sua redenção [...]" (LOPES, 1986, p. 19).

A atuação das Irmãs Dominicanas de Nossa Senhora do Rosário de Monteils em toda a extensão territorial da Diocese de Goiás com a fundação de colégios e o trabalho com as crianças e jovens, de princípio do sexo feminino, "faz parte da estratégia de reforma da igreja católica no que tange à reforma moral e religiosa da sociedade goiana", pois por meio dessas instituições escolares, a mocidade, em especial as meninas, seria educada com objetivos de "regenerar a sociedade por meio da família cristã, pela educação da mulher" (DOURADO, 2010, p. 135).

Conforme a historiografia, a presença de diversas ordens e congregações religiosas no Brasil durante a primeira república e a abertura e manutenção de colégios católicos dirigidos por elas significou a oferta de

\footnotetext{
1 “A diocese de Goiás fica rigorosamente no centro do Brasil [...] Além da própria província de Goiás, que, do sul ao norte, mede 2.000 quilômetros de extensão, e de este a oeste cerca de 850, em sua maior largura, a diocese compreendia ainda uma parte da província de Minas Gerais, o que se chama 'Triângulo Mineiro', território igual a quatro ou cinco departamentos franceses" (GALLAIS, 1942, p.58).
} 
um ensino humanístico na melhor tradição europeia, atraindo as elites que, ao matricularem seus filhos e suas filhas nessas instituições, legitimaram seu caráter civilizador e contribuíram para a sua manutenção e reprodução. Por outro lado, urge apontar, essa rede escolar católica trazia compensações econômicas e viabilizava, como nenhuma outra estratégia, o projeto de recatolização da sociedade brasileira empreendido pela ICAR [Igreja Católica Apostólica Romana], e ainda era de fundamental importância para o financiamento das congregações religiosas (AQUINO, 2012, p. 12-13).

Assim, as instituições escolares dominicanas-anastasianas existentes até os primeiros anos do século XX em Goiás, Colégio Sant'Anna, Colégio Santa Catarina de Sena e Colégio Sagrado Coração de Jesus inseriam-se no programa de romanização dos bispos brasileiros, como esclarece Medeiros Oliveira,

Em meio a essas discussões, é possível inferir, mais uma vez, a eminente preocupação e interesse da Igreja pela vinda das Congregações religiosas europeias para o Brasil e a consequente incumbência de disseminar o catolicismo romanizado por meio de suas instituições. A educação seria o meio, a romanização a finalidade e os princípios seriam os conhecimentos de Deus Criador e Onipotente. Nessa mesma diacronia, o projeto que se instalava ao final do século XIX e que seria o sustentáculo da nova era, tinha seu ideário fundado na Igreja, objetivando formar o homem republicano e católico (2010, p.160).

Estas instituições escolares estavam em consonância, também, com o grande projeto educativo, cultural, civilizatório e evangelizador da Ordem Dominicana para toda a região sertaneja de Goiás. Para as instituições escolares dominicanas-anastasianas afluíram famílias de todos os lugares, das cidades e estados vizinhos que buscavam oferecer aos filhos uma boa educação escolar (PIAGEM; SOUZA, 2000), tendo em vista que

o trabalho pedagógico desenvolvido pelas religiosas francesas visava uma educação centrada nos princípios morais, na disciplina, na formação religiosa, social e intelectual das moças [...] Um dos aspectos relevantes da pedagogia dominicana foi a ênfase na cultura, principalmente, nas artes manuais, no desenho, na culinária, na música, no estudo de línguas, em relevo o domínio do francês e no desenvolvimento da linguagem verbal [...] O sistema de ensino pautado pelos princípios da disciplina, da obediência, do respeito e dos bons exemplos, tendo por base a inculcação moral e religiosa, visava a formação de alunos dóceis, obedientes, mas, ao mesmo tempo, preparados para ocuparem, futuramente, posições e responsabilidades de mando. As permanentes atividades propostas aos alunos, o controle do espaço e do tempo eram importantes dispositivos utilizados pelas freiras para realizarem os seus objetivos educacionais. (DOURADO, 2010, p. 135-136). 
Em Porto Nacional, a influência do Colégio Sagrado Coração de Jesus foi incisiva e originou na cidade um clima europeu, de uma cultura mais refinada que agradou as famílias mais abastadas e chamou a atenção das mais pobres que, sacrificavam-se para colocar os filhos no colégio das religiosas. Como já destacado aqui, os colégios dominicanosanastasianos concediam benefícios e bolsas para os mais carentes em razão da existência de convênios com o poder público. Assim, por meio da legislação que facultava ao Estado subvencionar escolas primárias particulares tanto o colégio Sant'Anna, como o Sagrado Coração de Jesus passaram a receber recursos a partir de 1908 o que possibilitou o atendimento às meninas carentes (DOURADO, 2010).

A ressonância do Colégio Sagrado Coração de Jesus ao longo de todo o século XX no sertão do antigo norte goiano foi significativa e chegou ao século XXI marcando a educação do mais novo estado da federação brasileira, o Tocantins. Em pleno funcionamento, a instituição escolar consolidou-se em Porto Nacional e, atualmente, oferece a modalidade de educação básica. É reconhecida como uma instituição filantrópica, atende mais de 1500 alunos, mantém um currículo diferenciado, exigente e que dialoga com a atualidade e com as emergências do mundo pós-moderno embasado nos princípios da filosofia dominicana-anastasiana e nos valores éticos e cristãos (DOURADO, 2010; BRESSANIN, 2017).

A expansão do projeto educativo dominicano-anastasiano continuou para o interior da diocese e do estado de Goiás com a fundação em 1910 do Colégio São José na cidade de Formosa. Desde 1905 os frades dominicanos mantinham nesta cidade o seu apostolado missionário e entrando em acordo com a superiora da Congregação conseguiram que as Irmãs Maria Leonor, Maria Hilária, Maria Apolina e Madalena inaugurassem no dia 05 de abril de 1910 a escola para meninas, o Colégio São José (LOPES, 1986).

Este colégio destacou-se na região - considerada o coração geográfico do Brasil durante algumas décadas, especialmente, na formação das professoras normalistas. Afirma-se que a difusão do ensino primário em Formosa e nos arredores deve-se às normalistas formadas pelo Colégio São José (LOPES, 1986).

No entanto, em 1942, as Irmãs Dominicanas deixam a direção desta instituição escolar e a entregam ao bispo de Goiás da época, Dom Emanuel Gomes da Silva. Os frades já haviam se retirado da cidade alguns anos antes e, talvez pelas mesmas razões, as econômicas financeiras, as educadoras dominicanas "deixaram um vácuo e uma interrogação" (LOPES, 1986) nos alunos e na sociedade de Formosa. Em 1945, a Congregação das Religiosas Missionárias de Nossa Senhora das Dores, fundada por Madre Maria de Jesus, assumiu a direção do São José, a pedido de D. Emanuel (COLÉGIO SÃO JOSÉ DE FORMOSA, 2019).

Entre tantas histórias e memórias da missão de educar evangelizando e ministrando um ensino libertador à luz dos valores evangélicos no espírito de São Domingos e da prática educativa Madre Anastasie, o estado de Goiás constitui-se uma terra fértil para a educação dominicana-anastasiana no final do século XIX e ao longo do século XX.

Em 1933 erigiu-se a nova capital sertaneja do cerrado brasileiro, a cidade de Goiânia, "como ponto de partida de um novo período na história [...] de Goiás" (PALACIN, 1979, p. 92) e, também, da História da Educação goiana. No entanto, a educação dominicanaanastasiana chegou à recém inaugurada capital em 1948. Madre Maria Aimeé e as Irmãs Maria Celina, Gabriela da Imaculada e Maria Eulália instalaram-se em Goiânia no dia 07 de janeiro de 1948 vindas de Uberaba e de Goiás e fundaram o Colégio Externato São José que teve o início do ano letivo no dia 02 de março com três salas de aula da educação infantil e 125 alunos matriculados numa casa cedida pelo então prefeito da cidade de Goiás e pai de uma das educadoras religiosas (MELO, 2013).

Diferente das demais instituições escolares dominicanas-anastasianas no território goiano o Colégio Externato São José iniciou suas atividades educativas com turmas mistas. O contexto social, político e educacional brasileiro era outro. Viviam-se tempos 
de redemocratização do Brasil com o fim da Era Vargas, de modernização da sociedade brasileira com um processo mais acentuado de urbanização e o Estado passou a investir na industrialização e a se aparelhar melhor. No tocante à educação, "os anos quarenta caracterizam-se por reformas educacionais que passariam à história como as Leis Orgânicas do Ensino" (VIEIRA, 2007, p. 249).

Para além de sua função como centro político e administrativo do estado, Goiânia nasceu com a marca de modernidade, superando o isolamento social, político, cultural e econômico de Goiás em relação ao restante do país (GRANDE; BOAVENTURA, 2015). Foi planejada em meio a um horizonte brasileiro, na perspectiva da Marcha para o Oeste, pautandose em amplas transformações, novas definições políticas, econômicas e socioculturais em que o que estava em voga era o progresso, o desenvolvimento e a modernidade, fruto do governo Vargas e de políticos goianos como Pedro Ludovico (CHAUL, 2015).

No final do século XIX e nas primeiras décadas do século XX, a educação dominicana-anastasiana estava envolvida na fundação de colégios para a educação dos filhos das elites e voltada para uma educação feminina de acordo com as propostas ultramontanas e romanizadoras da Igreja Católica. No contexto do final da década de 1940, as religiosas dominicanas-anastasianas souberam adaptar-se às exigências do tempo e do espaço. Prestaram atenção ao que era real, ao que estava presente, às questões em disputa, aos desafios que a nova realidade acenava, mas sem esquecer-se dos princípios e das finalidades de sua identidade e de sua proposta educativa desde sempre: valorizar o indivíduo e enxergar o potencial de cada um (MC VEY, 2015, p. 114).

O Colégio Externato São José acompanhou o crescimento da capital Goiânia, rapidamente. Em 1953 lançou-se a pedra fundamental da construção do atual prédio que foi inaugurado em 1963 e ampliado ao longo do tempo em razão do crescente aumento do número de matrículas que chegou a 1300 alunos vinculados à educação infantil e ao ensino fundamental (CONGREGAÇÃ̃O DAS IRMÃS DOMINICANAS DE NOSSA SENHORA DO ROSÁRIO DE MONTEILS, 2016).

A Congregação das Irmãs Dominicanas de Nossa Senhora do Rosário de Monteils foi pioneira da educação católica no estado de Goiás. A educação dominicana-anastasiana foi a primeira a instalar-se em pleno sertão do cerrado brasileiro. Num tempo difícil em que as distâncias, a pobreza, as dificuldades e o isolamento marcava o cotidiano da população goiana e que o Estado pouco se preocupava, financiava ou estruturava o ensino, os colégios, escolas e institutos desta congregação ganharam destaque no campo educacional.

A educação dominicana-anastasiana deixou marcas indeléveis na construção da sociedade goiana, de norte a sul do Estado. Em plena expansão de suas instituições para outros grandes centros do Brasil como Rio de Janeiro, São Paulo e Brasília, os olhares de missão educativa voltam-se para uma região muito pobre conhecida como "corredor da miséria" no antigo norte de Goiás.

No final ano de 1957, após negociações entre o prefeito da cidade de Arraias, o deputado federal por Goiás, João de Abreu e o bispo diocesano de Porto Nacional, Dom Alano Maria Du Noday - dominicano e francês -, chegaram à Arraias, algumas religiosas dominicanas. O pedido de boa parte da população arraiana, que contava com muitas egressas normalistas do Colégio Sagrado Coração de Jesus de Porto Nacional e do Colégio São José de Formosa, fizeram com que a Madre Berta, a Irmã Maria das Graças, a Irmã Reginalda e a Irmã Liliosa viessem ao encontro dos anseios da sociedade, da igreja e do governo.

Na cidade já havia um grande prédio construído pelo poder público com a ajuda da comunidade local. Aproveitando-se dele as educadoras dominicanas-anastasianas aplicaram o exame de admissão ao ginásio. Formaram uma equipe de trabalho contando com as irmãs já residentes, outras religiosas que chegaram como Irmã Marilda, Maria das Graças e Maria da 
Natividade e alguns professores leigos da cidade. A partir desta equipe fundaram no dia 11 de fevereiro de 1958 o Instituto Nossa Senhora de Lourdes (COSTA, 2004). Arraias era uma

Cidade pacata, pequenina, fincada numa bacia circundada por colinas, longínquo e abandonado nordeste goiano, conceituado na época o corredor da miséria e sem nenhuma assistência na área da saúde [...] na educação, uma escola, por sorte com professores normalistas [...] o comércio era tímido e inexpressivo [...] Aquela avilssareira notícia de implantar uma escola e ainda dirigida por freiras, revolucionou a região reanimando a todos, pois apenas em Dianópolis havia um colégio, na região, o que dificultava a maioria dos jovens a dar continuidade aos estudos, devido as grandes dificuldades de se manter um estudante fora de casa (COSTA, 2004, p. 37).

Além do ensino ginasial, a oferta da Escola Normal Regional atraiu àqueles que queriam continuar seus estudos. Assim, em 1961 formou-se a primeira turma de professores normalistas pelo Instituto Nossa Senhora de Lourdes.

As irmãs dominicanas entregavam a primeira turma de professorandos à comunidade: um grupo de nove alunos, bem instruídos, moldados às leis divinas e humanas, um grupo de jovens que iria continuar a obra dominicana, pois a semente foi muito adubada, regada com carinho e cultivada com rigor e esmero (LOPES, 1986, p. 190).

O Instituto Nossa Senhora de Lourdes foi durante muitos anos a única escola da cidade e da região a oferecer o ensino ginasial e de segundo grau. Funcionou até 1982 quando por questões financeiras, pressionadas por uma situação caótica e sem possibilidade de continuar viabilizando a escola para quem não pudesse pagar, as religiosas dominicanas passaram o instituto para a poder público estadual que recebeu o nome de Colégio Estadual Joana Batista Cordeiro (LOPES, 1986; COSTA, 2004).

\section{Considerações finais}

Trazer à superfície os caminhos da educação dominicana-anastasiana em Goiás, a partir das instituições escolares da Congregação das Irmãs Dominicanas de Nossa Senhora do Rosário de Monteils, foi o que aqui se propôs. Talvez as pérolas e os corais que foram resgatados trouxeram à tona, além de um saber histórico que se pretendeu produzir, um rol de dúvidas e questionamentos sobre a 'materialidade', a 'representação' e a ‘apropriação' (MAGALHÃES, 2005) desses colégios, escolas e institutos em Goiás.

O anseio pela evangelização romanizadora expresso na posição das autoridades eclesiásticas do final do século XIX e primeiras décadas do século XX, comunga com a proposta educativa da Congregação de Monteils: a educação dominicana-anastasiana tem como finalidade, também, a evangelização. Além do mais, é notório um sentido, que às vezes, passa despercebido, mas que se afina com as intenções do episcopado brasileiro naquele contexto: o caráter civilizador expresso na institucionalização deste projeto educativo nos colégios dominicanos-anastasianos, especialmente no que concerne à educação feminina.

Mesmo que a filosofia da educação dominicana-anastasiana se assente em princípios éticos e cristãos na perspectiva de uma educação integral do ser, não há como deixar de se interrogar sobre aspectos que corroboram para acentuar a exclusão e a desigualdade: apesar do 
atendimento às crianças carentes nos diversos colégios, a razão principal de existir destas instituições escolares era o cuidado, a formação e a instrução da elite da sociedade goiana.

Apesar de inseridas num processo reformador e civilizador católico, especialmente para o estado de Goiás, ancoradas na iniciativa privada, atendendo prioritariamente a elite feminina das principais localidades do sertão goiano isso não reduz a importância das instituições dominicanas-anastasianas no processo de difusão da educação e de escolarização em Goiás.

Entre avanços e recuos ela construiu, apesar de não se institucionalizar desta forma, uma rede de educação em Goiás que estabeleceu marcas profundas e duradouras na cultura e na história da educação goiana. Como avanço, a consolidação de instituições escolares em pontos estratégicos do centro-sul ao norte do estado de Goiás. Como recuos, o fechamento de algumas delas, como o Colégio Sant'Anna após 126 anos de existência, ocasionadas pela crise econômica, inadimplência, migração dos alunos para escola pública e, principalmente, por falta de novas vocações para a vida religiosa que renova o grupo de irmãs educadoras na continuidade da implementação do projeto educativo dominicano-anastasiano.

\section{Referências}

AQUINO, Mauricio de. A Modernidade republicana e diocesanização do catolicismo no Brasil: a construção do bispado de Botucatu no sertão paulista (1890-1923). Tese (Doutorado em História). UNESP: Assis, 2012.

ARENDT, Hannah. Homens em tempos sombrios. São Paulo: Companhia das Letras, 2008.

AZZI, R. Vida religiosa feminina no Brasil Colonial (enfoques históricos). São Paulo: Paulinas, 1983.

AZZI, Riolando; BEOZZO, José Oscar (Orgs.). Os religiosos no Brasil: enfoques históricos. São Paulo: Paulinas, 1986.

BITTENCOURT, Agueda Bernardete. "A era das congregações - pensamento social, educação e catolicismo". Revista Pro-posições, v.28, n.3 (84), Set/Dez-2017. p.29-59. DOI: https://doi.org/10.1590/1980-6248-2016-0117.

BRESSANIN, César Evangelista Fernandes. A Ordem Dominicana nos sertões do norte: entre missões, desobrigas, construções e projetos educativos em Porto Nacional. Palmas: Nagô Editora, 2017.

BRETAS, Genesco F. História da instrução pública em Goiás. Goiânia: CEGRAF/UFG, 1991.

BRZEZINSKI, Iria. A formação do professor para o início da escolarização. Goiânia: UCG, 1987.

CAMARGO, Kenia G. F. Educação católica e presença dominicana em Goiás (GO): a cultura escolar do colégio Sant'Anna (1940-1960). Dissertação (mestrado em Educação) - Universidade Estadual de Mato Grosso do Sul, Unidade Universitária de Paranaíba. Paranaíba, MS: UEMS, 2014.

CANESIN, Maria Tereza; LOUREIRO, Walderez Nunes. A Escola Normal em Goiás. Goiânia: Editora da UFG, 1994. 
CHAUL, Nasr Nagib Faya. "Goiânia: a Capital do sertão". In: SILVA, Ademir Luiz da; OLIVEIRA, Eliézer Cerdoso de. (Org.). Goiânia em mosaico - visões sobre a capital do cerrado. Goiânia: Ed. da PUC Goiás, 2015.

COLÉGIO SÃO JOSE. http://www.colegiosaojoseformosa.com.br/nossa-escola/historia/. Acesso em 12 de março de 2019, às 18:45h.

CONGREGAÇÃO DAS IRMÃS DOMINICANAS DE NOSSA SENHORA DO ROSÁRIO DE MONTEILS. Família Dominicana: 800 anos tecendo história. São Paulo: Associação Educadora da Infância e Juventude, 2016.

COSTA, Magda Sueli Pereira. Educação e Cultura em Arraias. Palmas: Secretaria de Comunicação (SECOM), 2004.

DOURADO, Benvinda Barros. Educação no Tocantins: Ginásio Estadual de Porto Nacional. Tese (Doutorado em Educação) Universidade Federal de Goiás, Goiânia, 2010.

GALLAIS, Estevão. O Apóstolo do Araguaia: Frei Gil missionário dominicano. São Paulo: Revista dos Tribunais, 1942.

GATTI JR., D. "A história das instituições educacionais: inovações paradigmáticas e temáticas". In: ARAUJO, J, C. S.; GATTI Jr., D. (orgs.) Novos temas em História da Educação Brasileira: instituições escolares e educação na imprensa. Campinas, SP: Autores Associados; Uberlândia, EDUFU, 2002, p. 3-24.

GONÇALVES, A. M. Educação secundária feminina em Goiás: intramuros de uma escola católica: colégio Sant'Anna 1915/1937. Tese (Doutorado em Educação) - Universidade Estadual Paulista - Faculdade de Ciências e Letras, Campus de Araraquara, 2004.

GRANDE, Ivan Oliveira de; BOAVENTURA, Deusa Maria Rodrigues. "Contradições no centro tradicional de Goiânia: usos e transformações no espaço da praça cívica e Avenida Goiás". Revista PerCursos. Florianópolis, v.16, n.30, p.74-98. jan./abr.-2015. DOI: https://doi.org/10.5965/1984724616302015074.

KOSELLECK, Reinhart. Futuro passado: contribuição à semântica dos tempos históricos. Trad. do original alemão Wilma Patrícia Maas, Carlos Almeida Pereira; revisão da tradução César Benjamim. - Rio de Janeiro: Contraponto: Ed. PUC-RIO, 2006.

LEONARDI, P. Além dos espelhos, memórias, imagens e trabalhos de duas congregações católicas. São Paulo: Paulinas, 2010.

LOPES, Maria Antonieta Borges e BICHUTTE, Monica M. Teixeira Vale Bichutte (Org.) Dominicanas: cem anos de missão no Brasil. Uberaba: Vitória, 1986.

MAGALHÃES, Justino. A" história das instituições educacionais em perspectiva". In: GATTI JUNIOR, D. \& INÁCIO FILHO, G. (orgs.). História da educação em perspectiva: ensino, pesquisa, produção e novas investigações. Campinas: Autores Associados; Uberlândia: EDUFU, 2005. 
MCVERY, Chrys. "Valores dominicanos: atentos ao real e ao possível". In: KELLY, Gabriely; SAUNDERS, Kevin. Valores da educação dominicana: para o uso inteligente da liberdade. Tradução Sonia Midori Yamamoto. São Paulo: Edições Loyola: Editora Unesp, 2015.

MEDEIROS DE OLIVEIRA, Lúcia Helena Moreira de. "O projeto romanizador no final do século XIX: a expansão das instituições escolares confessionais”. Universidade do Estado de Goiás - UFG/JATAÍ. Revista HISTEDBR On-line, Campinas, n. 40, p. 145-163, dez. 2010. DOI: https://doi.org/10.20396/rho.v10i40.8639811.

MELO, Sandra Barbosa. Carisma Dominicano e prática educativa no Colégio Externato São José. Dissertação (Mestrado em Ciências da Religião) Pontifícia Universidade Católica de Goiás. Goiânia, 2013.

MELO. Geovana F. Por trás dos muros escolares: luzes e sombras na educação feminina. Colégio Nossa Senhora das Dores - Uberaba (1940-1966). Dissertação (Mestrado em Educação) Universidade Federal de Uberlândia. Uberlândia, 2002.

MICELI, S. Elite eclesiástica brasileira 1890-1930. São Paulo: Cia das Letras, 2009.

MOURA, Laércio Dias. A educação católica no Brasil. São Paulo: Loyola, 2000.

PALACIN, Luis. "Os três povoamentos de Goiás". Revista do Instituto Histórico e Geográfico de Goiás. Ano 7. № 8, Goiânia, 1979.

PESAVENTO, Sandra Jatahy. História \& História Cultural. Belo Horizonte: Autêntica, 2008. PIAGEM, Pedro P.; SOUSA, Cícero J. de. Dom Alano: o missionário do Tocantins. Goiânia: Autores, 2000.

ROUX, R. "La romanización de la Iglesia católica en América Latina: una estratégia de larga duración". Pro-Posições, 25(1), 31-54. Jan/abr-2014. DOI: https://doi.org/10.1590/S0103$\underline{73072014000100003 .}$

SAVIANI, Demerval. "Instituições escolares no Brasil: conceito e reconstrução histórica". In: NASCIMENTO, Maria Isabel Moura (et. al.) (Orgs.). Instituições escolares no Brasil: conceito e reconstrução histórica. Campinas, SP: Autores Associados: HISTEDBR; Sorocaba, SP: UNISO; Ponta Grossa, PR: UEPG, 2007.

SILVA, José Trindade da Fonseca e. Lugares e pessoas: subsídios eclesiásticos para a história de Goiás. Goiânia: UCG, 2006.

SMITH, Philip. "A filosofia dominicana da educação". In: KELLY, Gabriely; SAUNDERS, Kevin. Valores da educação dominicana: para o uso inteligente da liberdade. Tradução Sonia Midori Yamamoto. São Paulo: Edições Loyola: Editora Unesp, 2015.

VALLE, Irmã Maria Lucília Pereira. Colégio Sant'Ana - 100 Anos de Missão em Goiás. Goiânia: UCG, 1989.

VIEIRA, SOFIA Lerche. “A educação nas constituições brasileiras: texto e contexto”. Revista Brasileira Estudos Pedagógicos. Brasília, v.88, n.219, p.291-309, maio/ago.-2007. DOI: https://doi.org/10.24109/2176-6681.rbep.88i219.749. 